\title{
Kidney transplantation and donation in children
}

\author{
Ernest van Heurn · Eva E. de Vries
}

Accepted: 27 February 2009/Published online: 29 March 2009

(C) The Author(s) 2009. This article is published with open access at Springerlink.com

\begin{abstract}
It has been shown that kidney transplantation results in superior life expectancy and quality of life compared with dialysis treatment for patients with endstage renal disease. However, kidney transplantation in children differs in many aspects from adult kidney transplantation. This review focuses on specific issues of surgical care associated with kidney transplantation in children, including timing of transplantation, technical considerations, patient and graft survival, growth retardation and post-transplant malignancy. At the same time, there is a large discrepancy between the number of available donor kidneys and the number of patients on the waiting list for kidney transplantation. There is a general reluctance to use paediatric donor kidneys, because of relatively frequent complications such as graft thrombosis and early graft failure. We review the specific aspects of kidney transplantation from paediatric donors such as the incidence of graft thrombosis, hyperfiltration injury and 'en bloc' transplantation of two kidneys from one donor with an excellent long-term outcome, which is comparable with adult donor kidney transplantation. We also discuss the potential use of paediatric non-heart-beating donor kidneys, from donors whose heart stopped beating with the preservation techniques used.
\end{abstract}

Keywords Pediatric - Transplantation - Kidney · Non-heart-beating

E. van Heurn $(\varangle) \cdot$ E. E. de Vries

Department of Surgery, University Hospital Maastricht,

Maastricht, The Netherlands

e-mail: e.vanheurn@mumc.nl

\section{Introduction}

Kidney transplantation is the treatment of choice in children with end-stage renal disease (ESRD) with long-term benefits in patient survival and quality of life compared with dialysis. In children, kidney transplantation is associated with a number of specific problems such as a higher chance of graft failure, post-transplant malignancy, growth retardation, and it may be a technical challenge to transplant a relatively large adult size kidney into a small paediatric abdominal cavity.These factors play an important role to decide at which age children with ESRD are preferably transplanted. Specific aspects and the outcome of kidney transplantation in the paediatric age group are addressed.

There is a large discrepancy between the number of available donor kidneys and the number of patients on the waiting list for kidney transplantation. To expand the donor pool organs from marginal donors are increasingly used including organs from older donors and non-heart-beating (NHB) donors, donors who do not meet the brain death criteria but die after cardiac arrest. Kidneys from paediatric donors may also be suitable for transplantation, including paediatric kidneys from donors who meet the brain death criteria and kidneys from NHB donors. Special issues of paediatric organ donation are discussed.

\section{Timing}

There is no absolute minimum age for paediatric kidney transplantation. Before 1980, infants and young children were only rarely transplanted because the relatively high risk of early graft loss and the high mortality which exceeded $20 \%$ in some series of children in this age group 
$[1,2]$. However, more recently the results of renal transplantation in children have improved so that even infants with ESRD may be suitable candidates for renal transplantation. Many centres still prefer an age above 2 years and a weight above $15 \mathrm{~kg}$, but infants aged 6 months and weighing $<5 \mathrm{~kg}$ have been successfully transplanted [3].

One of the potential limitations for renal transplantation in children is the size of the donor kidney. In the United States more than $50 \%$ of the kidneys transplanted in children are from living, thus adult donors [4]. In the Eurotransplant region (Austria, Belgium, Croatia, Germany, Luxemburg, The Netherlands, Slovenia), this percentage is $20 \%$, but is increasing [5]. Transplantation of kidneys from donors younger than 5 years of age are preferably avoided in children as the risk of early graft failure is increased [6]. Therefore, adult size donor kidneys are almost universally used. Adult sized kidneys are placed into the paediatric abdominal cavity, usually without significant tension or respiratory compromise if the abdomen is closed.

A second potential disadvantage of kidney transplantation in infants and young children is the small blood volume and low cardiac output. These may be inadequate to guarantee sufficient perfusion of an adult size kidney, which is used to the higher blood pressure of the donor. Particularly ischaemically damaged grafts may easily fail if the early post-transplant blood pressure is too low [7].

Delay of kidney transplantation is associated with the loss of precious years of growth potential [3]. Furthermore, transplanted children have a superior quality of life and avoid complications which are associated with dialysis such as dialysis peritonitis or venous access problems. The optimal moment to transplant a child with ESRD is just before dialysis becomes necessary, if there is a donor available. With a goal to transplant an adult size kidney the general approach of the Stanford group is to perform the transplantation in children of approximately $10 \mathrm{~kg}$ and at least 6 months of age [3]. In children who do not tolerate dialysis or do not grow, transplantation can be done at lesser weight.

\section{Technical considerations}

In adults, the most common approach to transplant a kidney is extraperitoneally with an incision above the left or right groin. Kidneys are anastomosed with the common or external iliac artery and vein. In children this approach carries two disadvantages. First, there is a size mismatch between the available extraperitoneal space and the adult sized donor kidney, and, secondly, the recipient artery may be small compared with the artery of the graft that make the vascular anastomosis more difficult and may jeopardise the blood pressure and blood flow which is required for the donor kidney to survive. Therefore, kidney transplantation in children below the of age 5 years is generally done through a midline incision and the graft is placed into the peritoneal cavity. The donor vein is anastomosed with the caval vein of the recipient, which is clamped during the venous anastomosis. Immediately after the venous anastomosis has been completed, the clamp on the caval vein is released and the renal vein is selectively clamped with a bull dog. Next, the donor artery is either anastomosed with the distal aorta, to obtain the best arterial inflow, or with one of the common iliac arteries. The latter avoids a complete occlusion of the aorta which is associated with temporary acidosis of both lower extremities. The decision which artery is chosen depends on the size of the arteries and the position of the renal graft. The cold graft is placed in the preferred position. The donor vessels are often amputated and may be spatulated to ensure a wide anastomosis and to avoid kinking which may lead to impaired blood flow and to non-function of the graft. It is questionable if the graft has to be additionally cooled during the anastomosis time. It often requires a longer period of time to make an anastomosis in children than in adults, but given the size of the kidney and the absence of flow, the warming up is probably slow and unless there are technical difficulties the anastomosis time is not a risk factor for graft failure.

The ureter of an adult size kidney is long and wide enough to obtain a wide ureter-bladder anastomosis. The ureter is cut and shortened to obtain the best vascularisation of the anastomosis. Interrupted sutures of a spatulated ureter further minimise the risk of ureteral stenosis. Temporary ureteral stenting may reduce the risk of ureteral stenosis, but is associated with a higher risk of urinary infection. However, this can be successfully treated with antibiotics [8]. A further disadvantage of a stent is the need to remove it some weeks after transplantation.

Particularly in young children one of the main causes of ESRD is obstructive uropathy. Outflow obstruction, small capacity or poor function of the bladder predisposes to vesicoureteral reflux of the transplanted kidney. In these patients an antireflux procedure is imperative. There are different intra- and extravesical techniques to make a ureter-bladder anastomosis; the choice depends on the anatomy and previous surgery.

\section{Patient and graft survival}

The life expectancy of children with ESRD and a renal transplantation is an estimated 20-25 years shorter than of the normal population [9]. The high mortality in children is caused by associated cardiovascular disease and less 
frequently by infection $[10,11]$. Superior long-term results of kidney transplantation and prolonged immunosuppressive treatment may increase the future incidence of malignancy as important cause of transplant recipient death. It should be considered that the relatively poor longterm survival of children with ESRD is based on the relatively few and retrospective results. The results of paediatric transplantation and immunosuppression have improved substantially over the last decades with unknown effects on late survival. Presently, the 5-year patient survival after transplantation of children with ESRD is higher than $95 \%$ with only minimal difference between recipients of living and deceased donor grafts.

Graft survival following paediatric transplantation is highly dependent on donor source. Living donor recipients have better graft survival than deceased donor recipients. In the United States, Eurotransplant region and centres in the United kingdom the 5-year graft survival of living donor recipients is between 80 and $90 \%$ [5, 12, 13]. For deceased donor kidney recipients, the 5-year graft survival is 10$20 \%$ less than for living donor grafts depending on other risk factors such as recipient age, dialysis and the cause of ESRD.

The most common cause of graft failure in young recipients in the first year after transplantation is graft thrombosis. This complication results in almost universal graft loss [14]. Its incidence in children is between 2 and $3 \%$, but may be as high as $10 \%$ in children younger than 5 years [15]. The risk of graft thrombosis is further associated with previous treatment of peritoneal dialysis, deceased donor source, prior transplantation and prolonged cold ischaemia time. The use of the interleukin (IL)-2 receptor antagonists basiliximab and daclizumab as induction immunosuppressive therapy decreases the risk of graft failure due to thrombosis compared with other immunosuppression as OKT3 [15]. Acute rejection is a second important cause for early graft loss and depends amongst others on HLA-matching and the immunosuppressive regimen.

Despite the higher incidence of graft thrombosis and the inferior graft survival in the first year after transplantation, children aged 5 years or less have an excellent long-term graft outcome. Survival curves show a long-term graft survival advantage in recipients aged 5 years or less compared with older children and adolescents. This advantage is shown clearly by the United Network for Organ Sharing (UNOS) data with a estimated graft half-life of more than 26 years in living graft recipients [16]. In contrast, the half-life of a living donor graft in adolescents is below 10 years which is less than the graft survival in children aged 6-12 years and adults. This relatively poor outcome is caused by long-term adverse events rather than events in the first year after transplantation as the initial results of adolescent transplantation are excellent [17]. Poor compliance to immunosuppression is only partly responsible for the high incidence of graft loss [18]. In adolescents rejection, reversal outcomes are worse than in other age groups which supports the opinion that more vigorous immune response which decreases at older age may play an important role [4, 19, 20].

The most important cause of late graft failure is chronic rejection that accounts for almost one-third of the graft losses in a series of 7,123 paediatric transplant recipients [21]. Acute rejection is a strong correlate and risk factor for chronic rejection graft loss. Prior to transplantation and, in the United States, African American recipient are additional risk factors [21]. Long-term graft survival is better in nondialysed than in previously dialysed patients and largely depends on the duration of dialysis [22-24]. In a group of 1,113 European paediatric kidney transplant recipients the relative risk of graft failure increased with $67 \%$ in children with more than 2 years of dialysis compared with children with a pre-emptive transplantation [5]. Long-term graft survival further depends on the underlying disease, which prevalence is listed in Table 1. Structural abnormalities such as reflux, posterior urethral valves and congenital kidney disease have a better outcome than ESRD caused by focal segmental glomerulosclerosis (FSGS), membranoproliferative glomerulonephritis (MPGN)-2, or haemolytic uraemic syndrome (HUS) [13, 25, 26]. In recipients with the original diagnosis FSGS, the disease recurs in 30-40\% after transplantation. The percentage is adversely affected by young age at presentation and rapid progression to ESRD. In half of the patients with recurrence the graft fails. Therefore, the 5-year graft survival in recipients with FSGS is approximately $10 \%$ less than in other paediatric transplant recipients. MPGN is a rare kidney disease with complement deposits within the glomerular basement membrane and usually progresses to kidney failure. After transplantation, it recurs in most patients with a significantly worse 5-year graft survival than other pediatric transplant recipients: $50 \%$ versus 74\%, respectively [26]. Recurrence of HUS is reported in 50-70\% of the transplanted patients and is particularly high in atypical, no diarrhoeal HUS. Moreover,

Table 1 Primary kidney disease of transplanted children with endstage renal disease

\begin{tabular}{ll}
\hline End-stage renal disease & Prevalence $(\%)$ \\
\hline Structural and cystic disease & $53-57$ \\
Glomerulonephritis & $22-27$ \\
Metabolic disease & $3-5$ \\
Congenital nephritic syndrome & $3-4$ \\
Other & $6-10$ \\
Unknown & $3-8$ \\
\hline
\end{tabular}


there is a relatively very high incidence of early artery or vein thrombosis so that in $50 \%$ of patients with HUS graft loss will occur within a year after transplantation [27].

Residual voiding disorders in patients with neuropathies may also jeopardise late graft function due to high pressure reflux or recurrent urinary tract infection [28]. However, bladder augmentation or urinary diversion prior to transplantation reduces the risk of graft loss so that voiding disorders hardly influence eventual graft function or graft survival.

\section{Growth}

Growth retardation is an important side-effect of chronic renal insufficiency. It is caused by nutritional deficiencies, metabolic disturbances and effects on the growth hormone axis. Dialysis does not improve growth velocity or pubertal development [29]. Despite the pre-transplant use of growth hormone, the majority of young adults with ESRD have a height below -2SD score [30].

Renal transplantation may increase growth velocity in children with ESRD with eventual increase in the adult height. Factors that influence catch-up growth are age and height at the moment of renal failure, the moment of transplantation, level of transplant function and dose and frequency of corticosteroid treatment [31, 32]. Children younger than 4 years have the largest benefits from transplantation. Their growth velocity increases with more than $3 \mathrm{~cm} /$ year compared with children on dialysis [33]. In children who receive a transplant post-puberty, acceleration of growth velocity and adult height are much less than in children who are transplanted at younger age. Despite the positive influence of renal transplantation on growth velocity, the final adult height of children with ESRD remains less than of the normal population.

Corticosteroids, given after transplantation, have a negative influence on longitudinal growth that can be diminished by steroid-free immunosuppression or by the reduction of the frequency of administration from once daily to alternate daily $[34,35]$. The post-transplantation administration of growth hormone improves growth velocity in both pre-pubertal and pubertal children without effect on renal function or increase of the occurrence of acute rejections [36, 37].

\section{Post-transplant malignancy}

Malignancy is a major cause of post-transplant mortality and morbidity. With the increased post-transplant survival its incidence has increased in the last decades and the mortality in adult renal transplant recipients may be as high as 20\%, 10 years after transplantation [38]. In paediatric transplant recipients, the incidence of malignancy is lower but the number of transplant patients with long-term follow-up is relatively small and the incidence is rising [39]. In children with ESRD, the probability of developing a malignancy within 25 years after renal replacement therapy is estimated at $17 \%$.

The majority of malignancies in renal paediatric transplant patients are skin cancers (40-50\%), predominantly squamous cell carcinoma, and post-transplant lymphoproliferative disorders (PTLD) in approximately $30 \%$ of the transplanted patients. Other relatively common malignancies include gynecological tumours and Kaposi's sarcoma. Post-transplant malignancy is related to the cumulative doses of immunosuppression. The immune surveillance is decreased while the depressed immune system is stimulated by antigens from the transplanted tissue or organ, repeated infections and possible blood transfusions [40]. PTLD is promoted by Epstein-Barr virus (EBV) infection, which may be transferred from an EBV-positive donor organ to an EBV-negative recipient. EBV can also become more pathogenic in previously infected asymptomatic patients. The risk of PTLD depends on the patients age, on the immunosuppressive regimen and is greatest in the first year post-transplantation.

The risk of malignancy can be reduced by appropriate low dosing of immunosuppressive medication and by the use of less carcinogenic immunosuppressive agents such as sirolimus. Antiviral therapy to reduce PTLD in children after EBV-positive solid-organ transplantation seems logical but its value to prevent malignancy has not been proven. The treatment of post-transplantation malignancies includes local excision of skin cancer and chemotherapy for refractory PTLD. Standard chemotherapy for nonHodgkin lymphoma shows a high percentage of complete remission, but approximately $30 \%$ of the children still die within 2 years [41].

\section{Paediatric donors}

The first paediatric donor kidney transplantation was described in 1964. In the following decade, the number of paediatric donor kidneys increased but the quality of the organs was generally considered as poor with a relatively short graft survival and a high incidence of complications. In 1974, it was concluded from an analysis of the American College of Surgeons/National Institutes of Health Transplant Registry (ACS/NIH) database that these kidneys had an inferior but, given a shortage of donor organs, acceptable level of function in adults [42]. Since then, improved transplantation techniques and superior immunosuppression have improved the results of transplantation from 
paediatric donor kidneys, so that, apart from kidneys from donors younger than 5 years, this group of kidneys is increasingly seen as a valuable expansion of the donor pool. There is still reluctance to transplant donor kidneys from children aged $<5$ years. The technical surgical challenge, the high incidence of arterial and venous thrombosis, the relatively high incidence of early rejection and potential hyperfiltration damage to the transplanted kidney are risk factors for graft failure or may compromise graft function [6, 43-46]. Moreover, the renal mass of the small paediatric donor kidney may be insufficient to meet the metabolic demands of the larger recipient. There is a strong correlation between initial renal mass and the eventual graft function in adults [47]. On the other hand, young donor kidneys exhibit better capacity to adapt to the recipient organism. They are able to increase glomerular filtration, caused by a suggested reserve capacity for growth or compensatory hypertrophy [48].

The number of available paediatric donor kidneys has decreased over the last two decades. Data from the Organ Procurement and Transplantation Network (OPTN) in the United States shows that the percentage of the available paediatric donor kidneys from the total number of deceased donor kidneys has decreased from $27 \%$ in 1988 , to $19 \%$ in 1998 and to $10 \%$ in 2008 (donor age 0-17 years) [12]. Also, in the Eurotransplant region the proportion of pediatric donors has decreased from $9 \%$ in 1994 to 3,6\% in 2007 (donor age $0-15$ years) [49]. The distribution within this paediatric donor cohort remains the same with the vast majority of donors between the ages 11 and 18 years [12]. The reason of the relative decreased number of paediatric donors remains unknown, but extension of the adult donor criteria with donors of old age and non-heart beating (NHB) donors, and safety measures for children such as helmets for cyclists and seat belts in cars, with consequently a reduction of the number of brain dead children, may play an important role.

\section{Heart beating and NHB donor kidneys}

The majority of the paediatric organ donors are organs from heart beating (HB) donors, donors after brain death [12]. The organs are procured from a ventilated patient with intact circulation, so that the warm ischaemia time of the donor organs is very limited. Depending on the age of the donor, kidneys are procured as single kidneys or 'en bloc', so that both donor kidneys can be used in one recipient.

A minority of paediatric donor kidneys are obtained from NHB donors, donors who die after cardiac arrest. NHB donation is done when brain death cannot be assessed or if the criteria for brain death are not met. Owing to the
Table 2 The Maastricht categories of NHB donors

\begin{tabular}{ll}
\hline Category & Description \\
\hline 1 & Dead on arrival \\
2 & Unsuccessful resuscitation \\
3 & Awaiting cardiac arrest \\
4 & Cardiac arrest while brain dead \\
\hline
\end{tabular}

shortage of donor organs, NHB donation has been popularised over the last decade. Presently, 10-20\% of the adult donor kidneys in selected centers in the United States are from NHB donors; this percentage is increasing rapidly. In the Netherlands, this percentage has even mounted to $50 \%$ for adults. Other countries in Europe with a relatively large proportion of NHB donors include the United Kingdom and Spain. In Germany, legislation stipulates that organs can only be taken from brain dead donors and excludes NHB donation and transplantation. Although implementation of NHB donor programs within adult hospitals has substantially increased over the last few years, advancement in children's hospitals lags behind. More attention is drawn to find ways to implement protocols for paediatric NHB donation in the critical care setting of many centres. The percentage of paediatric NHB donors of the total number of paediatric donors in the United States has increased from $<1 \%$ in 1997 to $8 \%$ in 2006 [12]. In The Netherlands, $20 \%$ of paediatric donor kidneys in the past 20 years has been from NHB donors [49].

Non-heart-beating donors can be categorised in to four groups, which are listed in Table 2 [50]. Donation after withdrawal from treatment (category 3), usually when ventilator support is discontinued in the intensive care unit (ICU), or after cardiac arrest in brain dead donors (category 4) are considered as 'controlled donation', while donation of patients who have died outside the hospital (category 1) or who die after failed resuscitation (category 2) are referred to as uncontrolled. In the latter two, the inevitable period of warm ischaemia after circulatory arrest is not exactly known so that the warm ischaemic damage to the organs has to be estimated. To minimise warm ischaemic damage to the organs, it is essential to cool the organs as fast as possible. Different preservation techniques are possible.

\section{Preservation techniques}

In controlled donors treatment can be discontinued in the operating theatre or in the ICU.

When the heart has stopped beating, patient death is declared by an independent physician. After an obligatory no-touch period of $5 \mathrm{~min}$ without invasive actions to 
ensure irreversible brain damage that can be compared with brain death, a laparotomy can be performed to insert preservation catheters into one of the common iliac arteries or into the aorta. In this way, cold preservation fluid can be infused to preserve the organs. Next, the aorta is clamped below the diaphragm and the abdominal organs are additionally cooled by pouring cold saline into the peritoneal cavity. Patients who die in the ICU can be rushed to the operating theatres as soon as possible after death. It is essential that the procedure and the need for urgent preservation of the organs is carefully discussed with the parents or relatives.

In uncontrolled donors or if the parents are reluctant to a rush from the ICU, organs can be preserved at the bedside after the declaration of death with the help of a doubleballoon triple-lumen (DBTL) catheter [51]. This catheter allows organ preservation with the help of a minimal surgical procedure. The aorta is occluded proximally and at the bifurcation and the organs with the origin between the balloons are cooled (Fig. 1) [52]. A 16 Ch DBTL catheter is available for adults and adolescents with an intra-balloon distance of $25 \mathrm{~cm}$ and a fully inflated balloon diameter of $40 \mathrm{~mm}$ (AJ6516, Porgès, France) and a smaller $12 \mathrm{Ch}$ catheter for children between 5 years and approximately

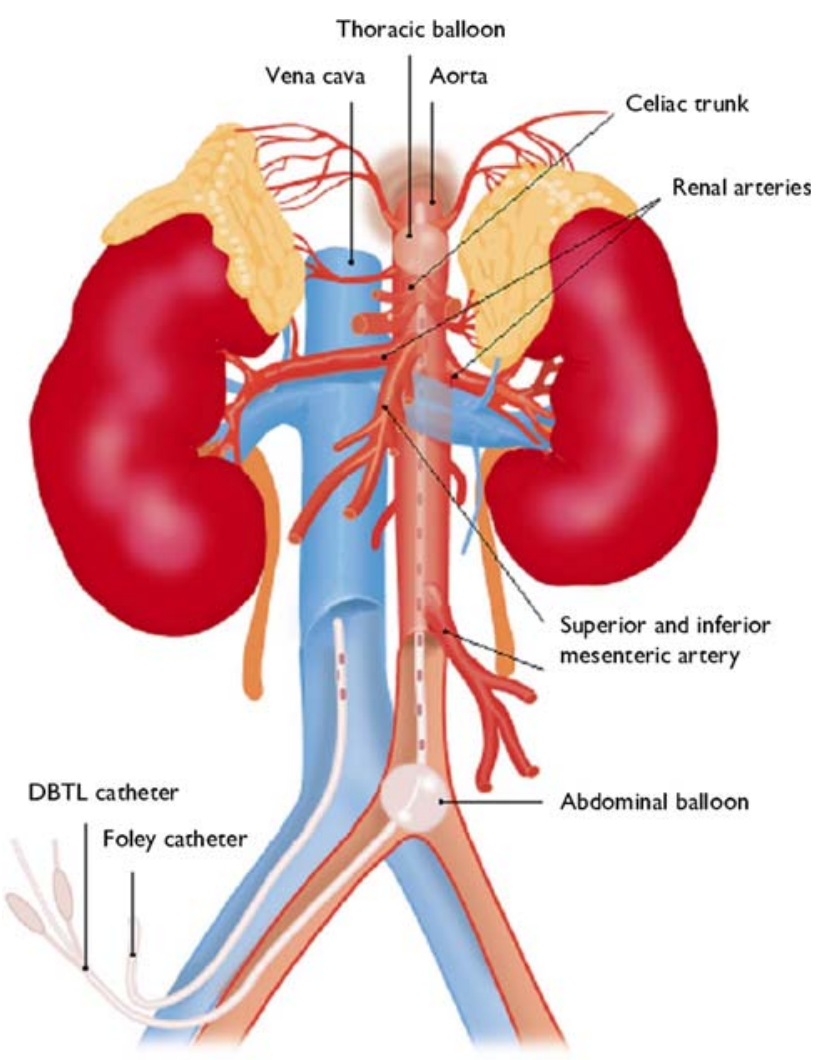

Fig. 1 In situ preservation with a double-balloon triple-lumen catheter
12 years of age, with an intra-balloon distance of $15 \mathrm{~cm}$ and a balloon diameter of $30 \mathrm{~mm}$ (61.630.12.080, Meddev, Holm, Germany). The choice for either catheter depends on the sex and the size of the child. The DBTL catheter is introduced into one of the femoral arteries through an arteriotomy. The abdominal balloon of the catheter is inflated with half of the maximum volume so that the balloon can be retracted until it hooks onto the aortic bifurcation. Subsequently, both the abdominal and the thoracic balloons are fully inflated and blood is drawn for chemistry, virological screening, and blood group typing. An infusion system is connected to the catheter and cold perfusate is infused until donor nephrectomy in the operating theatres. A Foley catheter into the femoral vein allows perfusate outflow. After the catheters have been fixed and the inguinal wound has been closed the parents or relatives have the opportunity to visit the deceased patient, before the patient goes to the operating theatre to procure the organs. According to Dutch legislation, in situ preservation is allowed before consent for donation is obtained from the relatives [53]. In case the relatives are not immediately available, this minimally invasive procedure ensures organ viability and empowers families with the opportunity to decide about donation [54].

A third method to preserve organs from NHB donors is to connect the donor to an extra corporeal membrane oxygenator (ECMO). This procedure is relatively complicated and has not been reported for children.

\section{Graft survival}

Early graft survival of paediatric donor kidneys is slightly lower than for adult donor kidneys, particularly for kidneys from the youngest donors. This difference is to a large extent caused by graft thrombosis, which is reported in $3.1-12.5 \%$ of the cases $[6,55-58]$. In the majority of the recipients with graft thrombosis, it is present within a week after transplantation, but it can also occur in a later stage [6]. It requires a meticulous surgical technique to anastomose a relatively small artery or vein. The anastomosis is easier if an aortic donor patch is used for the anastomosis instead of using the small, usually spatulated renal artery itself with a subsequent reduction in graft thrombosis. Other possible causes of graft thrombosis include a difference in blood pressure and vessel size between the donor and the recipient with turbulent and inadequate perfusion of the graft, torsion of the kidney and progressive thrombosis of a blind end of the aorta in 'en bloc' transplanted double kidneys [59].

Hyperfiltration, a consequence of the dissimilarity between donor and recipient weight, is one of the causes of late graft failure in recipients of paediatric donor kidneys. 
If the number of donor glomeruli is too small to filter the recipients blood volume adequately, the graft adapts to the recipients weight by hyperfiltration. This is invariably associated with the glomerular hypertrophy followed by glomerular sclerosis and progressive worsening of kidney function, eventually leading to exhaustion. Transplantation of a bigger nephron mass could prevent kidneys from hyperfiltration [60-62, 48]. One of the methods to prevent hyperfiltration in kidneys with a relatively small number of glomeruli such as kidneys from young children is by transplanting double grafts. This technique has been described in 1969 when a child received an 'en bloc 'kidney graft from an anencephalic infant and which has functioned for more than 30 years [63]. 'En bloc' transplantation is increasingly used for kidney from donors at young age with favourable results. Improved surgical techniques to transplant 'en bloc' kidneys have further enhanced pediatric kidney donor transplant survival. Age, kidney size, and donor weight are used to decide if donor kidneys should be transplanted as double grafts or as two single grafts for two different recipients including donor age $<1,<2,<3$ or $<5$ years, graft length $<6 \mathrm{~cm}$, and donor weight $<14 \mathrm{~kg}$ and $<21 \mathrm{~kg}$ [55-57, 64-69].

Early graft survival of paediatric donor transplants is slightly lower than of adult donor kidney transplants. An analysis of the UNOS in 12,838 patients shows a small but significant difference in graft survival between paediatric donors and adult donors in favour of the adult group. One and 5-year graft survival of 82 and $62 \%$, respectively, is reported after kidney transplantation from donors younger than 18 years and 84 and $62 \%$ after kidney transplantation from adult donors aged 18-50 [56, 69]. Kidneys from the youngest donors ( $0-5$ years) have lowest graft survival of 74 and $56 \%$ at 1 and 5 years $(n=2,198)$. A comparison of graft survival of 1,175 single transplants from pediatric donors and 24,530 single kidney transplants using 'ideal' deceased kidney donors between age 19 and 36 years demonstrated that recipients of kidneys from paediatric donors were at a significantly increased risk for graft loss. On the other hand double 'en bloc' transplanted kidneys from the youngest donor group, have similar graft survival as ideal donors [56, 69]. A limited number of relatively small series of paediatric donor kidneys even report a significantly better long-term outcome for 'en bloc' transplanted double paediatric kidneys once they survive the early postoperative course with 5-year survival rates of 76 and $82 \%[57,58]$. In these analyses survival is censored for early graft loss.

Little is known about the graft survival of NHB donor kidneys. Only a small series of 24 patients who received a paediatric NHB donor kidney shows excellent graft survival which is comparable with the results of transplantation of adult NHB donor kidneys [70].
Open Access This article is distributed under the terms of the Creative Commons Attribution Noncommercial License which permits any noncommercial use, distribution, and reproduction in any medium, provided the original author(s) and source are credited.

\section{References}

1. Kari JA, Romagnoli J, Duffy P, Fernando ON, Rees L, Trompeter RS (1999) Renal transplantation in children under 5 years of age. Pediatr Nephrol 13(9):730-736. doi:10.1007/s004670050689

2. Najarian JS, Frey DJ, Matas AJ, Gillingham KJ, So SS, Cook M et al (1990) Renal transplantation in infants. Ann Surg 212(3):353-365. doi:10.1097/00000658-199009000-00014 discussion 66-67

3. Salvatierra O Jr, Millan M, Concepcion W (2006) Pediatric renal transplantation with considerations for successful outcomes. Semin Pediatr Surg 15(3):208-217. doi:10.1053/j.sempedsurg. 2006.03.007

4. Hwang AH, Cho YW, Cicciarelli J, Mentser M, Iwaki Y, Hardy BE (2005) Risk factors for short- and long-term survival of primary cadaveric renal allografts in pediatric recipients: a UNOS analysis. Transplantation 80(4):466-470. doi:10.1097/01.tp. 0000168090.19875.b0

5. Cransberg K, Smits JM, Offner G, Nauta J, Persijn GG (2006) Kidney transplantation without prior dialysis in children: the Eurotransplant experience. Am J Transplant 6(8):1858-1864. doi: 10.1111/j.1600-6143.2006.01405.x

6. Singh A, Stablein D, Tejani A (1997) Risk factors for vascular thrombosis in pediatric renal transplantation: a special report of the North American Pediatric Renal Transplant Cooperative Study. Transplantation 63(9):1263-1267. doi:10.1097/00007890199705150-00012

7. Snoeijs MG, Wiermans B, Christiaans MH, van Hooff JP, Timmerman BE, Schurink GW et al (2007) Recipient hemodynamics during non-heart-beating donor kidney transplantation are major predictors of primary nonfunction. Am J Transplant 7(5):1158-1166. doi:10.1111/j.1600-6143.2007.01744.x

8. Wilson CH, Bhatti AA, Rix DA, Manas DM (2005) Routine intraoperative stenting for renal transplant recipients. Transplantation 80(7):877-882. doi:10.1097/01.tp.0000181197.21706.fa

9. Levey AS (1998) Controlling the epidemic of cardiovascular disease in chronic renal disease: where do we start? Am J Kidney Dis 32(5)(Suppl 3):S5-S13. doi:10.1053/ajkd.1998.v32.pm9820463

10. Groothoff JW, Gruppen MP, Offringa M, Hutten J, Lilien MR, Van De Kar NJ et al (2002) Mortality and causes of death of endstage renal disease in children: a Dutch cohort study. Kidney Int 61(2):621-629. doi:10.1046/j.1523-1755.2002.00156.x

11. Oh J, Wunsch R, Turzer M, Bahner M, Raggi P, Querfeld U et al (2002) Advanced coronary and carotid arteriopathy in young adults with childhood-onset chronic renal failure. Circulation 106(1):100-105. doi:10.1161/01.CIR.0000020222.63035.C0

12. Magee JC, Krishnan SM, Benfield MR, Hsu DT, Shneider BL (2008) Pediatric transplantation in the United States, 1997-2006. Am J Transplant 8(4 Pt 2):935-945. doi:10.1111/j.1600-6143. 2008.02172.x

13. Rees L, Shroff R, Hutchinson C, Fernando ON, Trompeter RS (2007) Long-term outcome of paediatric renal transplantation: follow-up of 300 children from 1973 to 2000. Nephron 105(2): c68-c76. doi:10.1159/000097601

14. Smith JM, Stablein D, Singh A, Harmon W, McDonald RA (2006) Decreased risk of renal allograft thrombosis associated with interleukin-2 receptor antagonists: a report of the NAPRTCS. Am J Transplant 6(3):585-588. doi:10.1111/j.1600-6143. 2005.01213.x 
15. McDonald RA, Smith JM, Stablein D, Harmon WE (2003) Pretransplant peritoneal dialysis and graft thrombosis following pediatric kidney transplantation: a NAPRTCS report. Pediatr Transplant 7(3):204-208. doi:10.1034/j.1399-3046.2003.00075.x

16. Sarwal MM, Cecka JM, Millan MT, Salvatierra O Jr (2000) Adult-size kidneys without acute tubular necrosis provide exceedingly superior long-term graft outcomes for infants and small children: a single center and UNOS analysis. United Network for Organ Sharing. Transplantation 70(12):1728-1736. doi: 10.1097/00007890-200012270-00012

17. Magee JC, Bucuvalas JC, Farmer DG, Harmon WE, HulbertShearon TE, Mendeloff EN (2004) Pediatric transplantation. Am J Transplant 4(Suppl 9):54-71. doi:10.1111/j.1600-6143.2004. 00398.x

18. Cecka JM, Gjertson DW, Terasaki PI (1997) Pediatric renal transplantation: a review of the UNOS data. United Network for Organ Sharing. Pediatr Transplant 1(1):55-64

19. Smith JM, Ho PL, McDonald RA (2002) Renal transplant outcomes in adolescents: a report of the North American Pediatric Renal Transplant Cooperative Study. Pediatr Transplant 6(6): 493-499. doi:10.1034/j.1399-3046.2002.02042.x

20. Burns EA, Leventhal EA (2000) Aging, immunity, and cancer. Cancer Control 7(6):513-522

21. Tejani A, Ho PL, Emmett L, Stablein DM (2002) Reduction in acute rejections decreases chronic rejection graft failure in children: a report of the North American Pediatric Renal Transplant Cooperative Study (NAPRTCS). Am J Transplant 2(2):142-147. doi:10.1034/j.1600-6143.2002.020205.x

22. Meier-Kriesche HU, Kaplan B (2002) Waiting time on dialysis as the strongest modifiable risk factor for renal transplant outcomes: a paired donor kidney analysis. Transplantation 74(10):13771381. doi:10.1097/00007890-200211270-00005

23. Cosio FG, Alamir A, Yim S, Pesavento TE, Falkenhain ME, Henry ML et al (1998) Patient survival after renal transplantation: I. the impact of dialysis pre-transplant. Kidney Int 53(3):767772. doi:10.1046/j.1523-1755.1998.00787.x

24. Kennedy SE, Mackie FE, Rosenberg AR, McDonald SP (2006) Waiting time and outcome of kidney transplantation in adolescents. Transplantation 82(8):1046-1050. doi:10.1097/01.tp. 0000236030.00461.f4

25. Fine RN (2007) Recurrence of nephrotic syndrome/focal segmental glomerulosclerosis following renal transplantation in children. Pediatr Nephrol 22(4):496-502. doi:10.1007/s00467006-0361-6

26. Braun MC, Stablein DM, Hamiwka LA, Bell L, Bartosh SM, Strife CF (2005) Recurrence of membranoproliferative glomerulonephritis type II in renal allografts: the North American Pediatric Renal Transplant Cooperative Study experience. J Am Soc Nephrol 16(7):2225-2233. doi:10.1681/ASN.2005020175

27. Sellier-Leclerc AL, Fremeaux-Bacchi V, Dragon-Durey MA, Macher MA, Niaudet P, Guest G et al (2007) Differential impact of complement mutations on clinical characteristics in atypical hemolytic uremic syndrome. J Am Soc Nephrol 18(8):23922400. doi:10.1681/ASN.2006080811

28. Adams J, Mehls O, Wiesel M (2004) Pediatric renal transplantation and the dysfunctional bladder. Transpl Int 17(10):596-602. doi:10.1111/j.1432-2277.2004.tb00392.x

29. Hutchings RH, Hickman R, Scribner BH (1966) Chronic hemodialysis in a pre-adolescent. Pediatrics 37(1):68-73

30. Fine RN, Ho M, Tejani A (2001) The contribution of renal transplantation to final adult height: a report of the North American Pediatric Renal Transplant Cooperative Study (NAPRTCS). Pediatr Nephrol 16(12):951-956. doi:10.1007/s004670100002

31. Qvist E, Marttinen E, Ronnholm K, Antikainen M, Jalanko H, Sipila I et al (2002) Growth after renal transplantation in infancy or early childhood. Pediatr Nephrol 17(6):438-443. doi:10.1007/ s00467-002-0850-1

32. Tejani A, Fine R, Alexander S, Harmon W, Stablein D (1993) Factors predictive of sustained growth in children after renal transplantation. The North American Pediatric Renal Transplant Cooperative Study. J Pediatr 122(3):397-402. doi:10.1016/ S0022-3476(05)83423-7

33. Turenne MN, Port FK, Strawderman RL, Ettenger RB, Alexander SR, Lewy JE et al (1997) Growth rates in pediatric dialysis patients and renal transplant recipients. Am J Kidney Dis 30(2):193-203. doi:10.1016/S0272-6386(97)90052-4

34. Hokken-Koelega AC, k Keizer-Schrama SM, Drop SL (1994) Effects of alternate-day or daily prednisone treatment on GH and cortisol levels in growth-retarded children after renal transplantation. J Pediatr Endocrinol Metab 7(2):119-125

35. Sarwal MM, Vidhun JR, Alexander SR, Satterwhite T, Millan M, Salvatierra O Jr (2003) Continued superior outcomes with modification and lengthened follow-up of a steroid-avoidance pilot with extended daclizumab induction in pediatric renal transplantation. Transplantation 76(9):1331-1339. doi:10.1097/01.TP. 0000092950.54184.67

36. Haffner D, Schaefer F, Nissel R, Wuhl E, Tonshoff B, Mehls O (2000) Effect of growth hormone treatment on the adult height of children with chronic renal failure. German Study Group for Growth Hormone Treatment in Chronic Renal Failure. N Engl J Med 343(13):923-930. doi:10.1056/NEJM200009283431304

37. Fine RN, Stablein D, Cohen AH, Tejani A, Kohaut E (2002) Recombinant human growth hormone post-renal transplantation in children: a randomized controlled study of the NAPRTCS. Kidney Int 62(2):688-696. doi:10.1046/j.1523-1755.2002.00489.x

38. Penn I (1997) Kaposi's sarcoma in transplant recipients. Transplantation 64(5):669-673. doi:10.1097/00007890-199709150-00001

39. Giessing M, Muller D, Winkelmann B, Roigas J, Loening SA (2007) Kidney transplantation in children and adolescents. Transplant Proc 39(7):2197-2201. doi:10.1016/j.transproceed. 2007.07.011

40. Buell JF, Gross TG, Thomas MJ, Neff G, Muthiah C, Alloway R et al (2006) Malignancy in pediatric transplant recipients. Semin Pediatr Surg 15(3):179-187. doi:10.1053/j.sempedsurg.2006.03.005

41. Gross TG, Bucuvalas JC, Park JR, Greiner TC, Hinrich SH, Kaufman SS et al (2005) Low-dose chemotherapy for EpsteinBarr virus-positive post-transplantation lymphoproliferative disease in children after solid organ transplantation. J Clin Oncol 23(27):6481-6488. doi:10.1200/JCO.2005.08.074

42. Merkel FK, Ing TS, Ahmadian Y, Lewy P, Ambruster K, Oyama $\mathrm{J}$ et al (1974) Transplantation in and of the young. J Urol 111(5): $679-686$

43. Hayes JM, Novick AC, Streem SB, Hodge EE, Bretan PN, Graneto D et al (1988) The use of single pediatric cadaver kidneys for transplantation. Transplantation 45(1):106-110. doi: 10.1097/00007890-198801000-00024

44. Nghiem DD (1991) En bloc transplantation of kidneys from donors weighing less than $15 \mathrm{~kg}$. into adult recipients. J Urol 145(1):14-16

45. Terasaki PI, Gjertson DW, Cecka JM, Takemoto S, Cho YW (1997) Significance of the donor age effect on kidney transplants. Clin Transplant 11(5 Pt 1):366-372

46. Modlin C, Novick AC, Goormastic M, Hodge E, Mastrioanni B, Myles J (1996) Long-term results with single pediatric donor kidney transplants in adult recipients. J Urol 156(3):890-895. doi: 10.1016/S0022-5347(01)65652-0

47. Kim YS, Moon JI, Kim DK, Kim SI, Park K (2001) Ratio of donor kidney weight to recipient bodyweight as an index of graft function. Lancet 357(9263):1180-1181. doi:10.1016/S0140-6736 (00)04377-4 
48. Feltran Lde S, Nogueira PC, Bocaletti AP, Christofalo DM, Ajzen SA, Pacheco-Silva A (2005) Assessment of factors determining graft size in transplant of cadaver kidneys from child donors. Transplantation 79(12):1731-1736. doi:10.1097/01.TP. 0000161057.16345.FB

49. NTS NTS: Annual Reports 1994-2007. Dutch Transplant Foundation. 2007

50. Kootstra G, Daemen JH, Oomen AP (1995) Categories of nonheart-beating donors. Transplant Proc 27(5):2893-2894

51. Snoeijs MG, Dekkers AJ, Buurman WA, van den Akker L, Welten RJ, Schurink GW et al (2007) In situ preservation of kidneys from donors after cardiac death: results and complications. Ann Surg 246(5):844-852

52. Kootstra G, van Hooff JP (1998) In situ preservation of kidneys of 'non-heart-beating' donors: a possible way to offset the shortage of donor kidneys. Ned Tijdschr Geneeskd 142(52): 2838-2843

53. Kootstra G, van Heurn E (2007) Non-heartbeating donation of kidneys for transplantation. Nature Clin Pract Nephrol 3(3):154 163

54. Kowalski AE, Light JA, Ritchie WO, Sasaki TM, Callender CO, Gage F (1996) A new approach for increasing the organ supply. Clin Transplant 10(6 Pt 2):653-657

55. Dharnidharka VR, Stevens G, Howard RJ (2005) En-bloc kidney transplantation in the United states: an analysis of united network of organ sharing (UNOS) data from 1987 to 2003. Am J Transplant 5(6):1513-1517. doi:10.1111/j.1600-6143.2005.00878.x

56. Bresnahan BA, McBride MA, Cherikh WS, Hariharan S (2001) Risk factors for renal allograft survival from pediatric cadaver donors: an analysis of united network for organ sharing data. Transplantation 72(2):256-261. doi:10.1097/00007890200107270-00016

57. Sureshkumar KK, Reddy CS, Nghiem DD, Sandroni SE, Carpenter BJ (2006) Superiority of pediatric en bloc renal allografts over living donor kidneys: a long-term functional study. Transplantation 82(3):348-353. doi:10.1097/01.tp.0000228872.89572.d3

58. Sanchez-Fructuoso AI, Prats D, Perez-Contin MJ, Marques M, Torrente J, Conesa J et al (2003) Increasing the donor pool using en bloc pediatric kidneys for transplant. Transplantation 76(8): 1180-1184. doi:10.1097/01.TP.0000090395.98045.09

59. Mohanka R, Basu A, Shapiro R, Kayler LK (2008) Single versus en bloc kidney transplantation from pediatric donors less than or equal to $15 \mathrm{~kg}$. Transplantation 86(2):264-268

60. Brenner BM, Meyer TW, Hostetter TH (1982) Dietary protein intake and the progressive nature of kidney disease: the role of hemodynamically mediated glomerular injury in the pathogenesis of progressive glomerular sclerosis in aging, renal ablation, and intrinsic renal disease. N Engl J Med 307(11):652-659

61. Brenner BM, Lawler EV, Mackenzie HS (1996) The hyperfiltration theory: a paradigm shift in nephrology. Kidney Int 49(6):1774-1777. doi:10.1038/ki.1996.265

62. Terasaki PI, Koyama H, Cecka JM, Gjertson DW (1994) The hyperfiltration hypothesis in human renal transplantation. Transplantation 57(10):1450-1454. doi:10.1097/00007890-19940527000008

63. Martin LW, Gonzalez LL, West CD, Swartz RA, Sutorius DJ (1969) Homotransplantation of both kidneys from an anencephalic monster to a 17 pound boy with Eagle-Barret syndrome. Surgery 66(3):603-607

64. Strey C, Grotz W, Mutz C, Pisarski P, Furtwaengler A, Bluemke $M$ et al (2002) Graft survival and graft function of pediatric en bloc kidneys in paraaortal position. Transplantation 73(7):10951099. doi:10.1097/00007890-200204150-00014

65. Hobart MG, Modlin CS, Kapoor A, Boparai N, Mastroianni B, Papajcik D et al (1998) Transplantation of pediatric en bloc cadaver kidneys into adult recipients. Transplantation 66(12): 1689-1694. doi:10.1097/00007890-199812270-00020

66. Portoles J, Maranes A, Prats D, Torrente J, Marron B, PerezContin MJ et al (1996) Double renal transplant from infant donors. A good alternative for adult recipients. Transplantation 61(1):37-40. doi:10.1097/00007890-199601150-00009

67. Bretan PN Jr, Friese C, Goldstein RB, Osorio RW, Tomlanovich S, Amend W et al (1997) Immunologic and patient selection strategies for successful utilization of less than $15 \mathrm{~kg}$ pediatric donor kidneys-long term experiences with 40 transplants. Transplantation 63(2):233-237. doi:10.1097/00007890-19970127000010

68. Borboroglu PG, Foster CE 3rd, Philosophe B, Farney AC, Colonna JO, Schweitzer EJ et al (2004) Solitary renal allografts from pediatric cadaver donors less than 2 years of age transplanted into adult recipients. Transplantation 77(5):698-702. doi:10.1097/01. TP.0000114462.10593.9F

69. Pelletier SJ, Guidinger MK, Merion RM, Englesbe MJ, Wolfe RA, Magee JC et al (2006) Recovery and utilization of deceased donor kidneys from small pediatric donors. Am J Transplant 6(7):1646-1652. doi:10.1111/j.1600-6143.2006.01353.x

70. Naim MY, Hoehn KS, Hasz RD, White LS, Helfaer MA, Nelson RM (2008) The Children's Hospital of Philadelphia's experience with donation after cardiac death. Crit Care Med 36(6):1729_ 1733. doi:10.1097/CCM.0b013e318174dd3d 